\title{
THE USE OF DIRECT MARKETING TECHNIQUES
} IN SPORT MARKETING

\author{
Daniel Adrian GÂRDAN ${ }^{1}$, Gheorghe EPURAN ${ }^{2}$, \\ Iuliana Petronela GÂRDAN ${ }^{1}$ \\ 1 “Spiru Haret”' University, Ion Ghica Street, no. 13, Bucharest, 030045, \\ Romania, Tel.: +40214551000, Fax: +40213143900, \\ Email:danielgardan@yahoo.com,geangupetronela@yahoo.com \\ ${ }^{2}$ Transilvania University of Braşov, Eroilor Blvd., no. 29, Braşov, \\ Email:gheorghe_epuran@yahoo.fr
}

\begin{abstract}
Adapting marketing principles and concepts to sport related services and products domain represents a challenge for any specialist in the field because of the specific features that are characteristic for the needs, motivations and consumption process itself.

In order to achieve different quantitative and qualitative marketing communication objectives, sports involved organizations are developing a communication mix adapted to the channels used by the consumers. Among the communication tools used are found also the direct marketing techniques that have had a tremendous development during the last 25 years and so.

The article will analyze the process of building an efficient direct marketing communication with sport consumers and the implications of using such instruments and tools for the future activity of sport related organizations. Some future research lines are proposed and conclusions are stated on the matter.
\end{abstract}

Keywords: direct marketing; sport marketing; sports loyalty.

JEL Classification: M31, M39, Z29 
Issue 4/2015

\section{Introduction}

Direct marketing techniques have been developed and used within the marketing activity in a more functional way beginning with the 70's.

In time, it has been developed a fully integrated direct marketing system that was offering for different organizations the possibility to have a personal dialogue with customers and other groups of stakeholders (like supporters, media, administration etc.).

The need for personal contact and communication has been increasing over time and direct marketing was able to offer a one-to-one communication meant to supply for information in order to facilitate the selling process.

This type of communication is encompassing a wide range of media within direct marketing campaigns directed to specific sets of objectives.

The direct marketing process is having not only the communication activities but also the creation, development and maintenance of an entire customer information system for organizations, activities grouped under the customer databases management umbrella.

The current users and the potential ones are implied alike in the process. Databases are adapted to the specific of the organization, the customers' type and the marketing objectives identified, thus they can have different levels of complexity from a mere alphabetic list of names to an advanced computer program having the possibility to offer cross-referencing and in depth checking.

Direct marketing will bring a lot of potential ways for every organization to have a more efficient marketing strategy adapted to different types of products and services and different kinds of consumption processes.

In case of sports involved organizations, sport products and sport related services require a direct and powerful mean of communication with consumers and sport fans. In this context using direct marketing techniques can make the difference between a successful communication that stresses a quick response for the needs of sport consumers and an approach incapable to deal with the fast changes imposed by competitors and socio-cultural shifts of lifestyles and consumption cultures. 

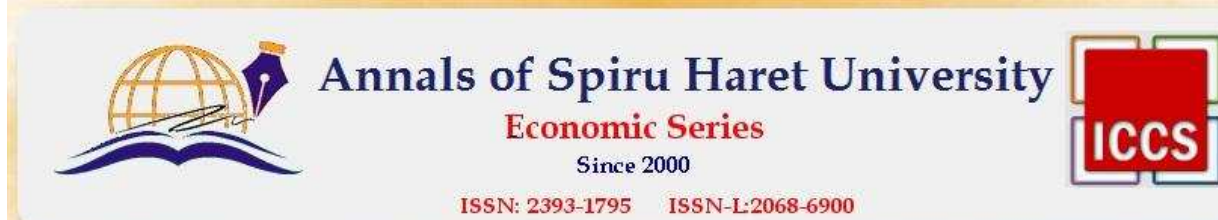

Issue 4/2015

The main objectives that an organization can achieve through direct marketing are the creation of a viable relationship with consumers, the dialogue and immediate sales or transactions. Besides this, organizations implied in the sports field can maintain a strong bound with their consumers, sports fans etc., through direct marketing channels, responding to their imperative need to be informed and to have a fast feedback concerning their needs.

Latest achievements in the field of direct marketing allow producers, players and sports club administrators the possibility to create and manage different types of customer complex databases along with an impressive flow of information between these databases and them.

\section{New achievements in direct marketing - specific traits}

The constant evolution of direct marketing was determined by at least two main streams of influential factors: social ones and business type ones.

From the point of view of the social field, it can be considered: [Tapp, 2005] fragmentation of the society, proliferation of media, greater consumer sophistication, the consumers' need of control. From the business field we may take into account the following: increased competition, the need for cost-effectiveness, greater interest in customer retention and loyalty from the management point of view, the dropping costs of the information computer processing services.

Taking account of these factors, in present we can emphasize some trends that are showing the new achievements in direct marketing:

- The use of QR codes on a large scale (especially when we talk about sports products it can be seen the tremendous effect of these innovative techniques in campaigns for well-known brands like Nike or Adidas).

- Integration of different sensorial inputs within the mail packages (especially smell and touch using different layers of paper).

- The use of email messages that have integrated within them video-files using the technology called video in print. 
Issue 4/2015

- The use of dimensional mail - being any kind of mail greater than 75 inches' box with different shapes and forms.

- The email has become an effective marketing communication tool with $39 \$$ return of investment for every dollar spent. $98 \%$ of the millennials are checking their emails at least every few hours at work [Naragon, 2015].

- The organic search will become more and more important as consumers are searching taking account of their search habits, there are over 12 billion web searches only in the US each month (http://www.hubspot. com/marketing-statistics).

- Mobile traffic has overcome the traffic made using desktop computers in ten countries. [Dischler, 2015] In addition, mobile devices are used for $60 \%$ of the digital media time in the US [Lella, \& Lipsman, 2014].

- The technology that allows the auto-play feature of videos within social media pages makes people to favour more and more this kind of content, as the nowadays society is obsessed with speed and the quantity of information also has increased.

- Mobile video advertising grew with $192 \%$ in 2014 and reached $50 \%$ from the total worldwide volume of social ad market that will have 19.8 billion dollars by the end of 2015. [Morrison, 2015]

- The so called "personalization" of direct marketing messages like the signature of the sales/marketing manager at the end of a letter is not effective anymore. Customers are waiting for real efforts regarding the personalization of the marketing communication.

- Facebook groups will become more effective in terms of building a viable platform for news feeds that are relevant for their members, not having the quantity of annoying information that a normal individual's Facebook feed has.

- An effective method for direct communication is related to the support actions for individual entrepreneurs. More brands are taking into consideration to improve their image through being supportive for different individual projects of entrepreneurs. These actions followed by a direct communication with the persons supported could be very effective in terms of creating a strong positive social image. 
The importance of direct marketing channels like mobile media, mobile apps etc. can be seen from the graphic below, as the data shows that total time spent by users with smartphone apps, mobile apps and mobile in general is increasing, reaching $65 \%$ for mobile only until the end of 2015 .

This trend is very representative for the evolution of direct marketing techniques in present time, this evolution being closely interlinked with the one of information technology itself. Year after year as much as the degree of familiarity with the technology grows for an increasingly larger part of consumers, integration of such technology within direct marketing efforts becomes not only a possibility but a necessity.

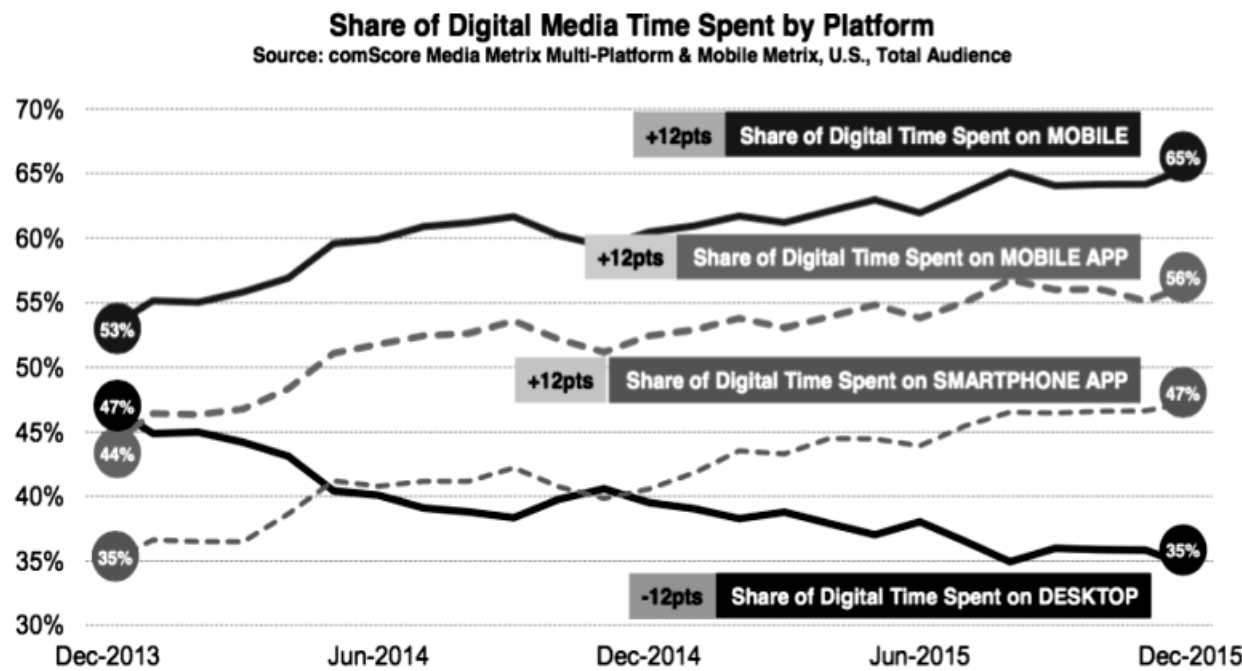

Figure no. 1. The time spent by users on different platforms

Source: Lella, A., Lipsman, A., \& Martin, B. (2015), The 2015 US Mobile App Report, comScore Media Metrix Multi-Platform \& Mobile Metrix, https://www.comscore.com/Insights/Presentations-and-Whitepapers/2015/The-2015-USMobile-App-Report

The need to be connected through internet related channels like the usual email has become so important that has transformed overnight into a 


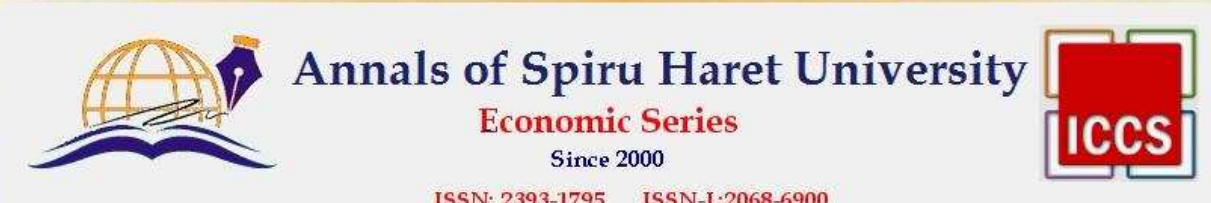

Issue 4/2015

social feature of modern consumers. As it can be seen from an Adobe research, adults are spending on average 6 hours per day to check emails, from 30 hours during a work week.

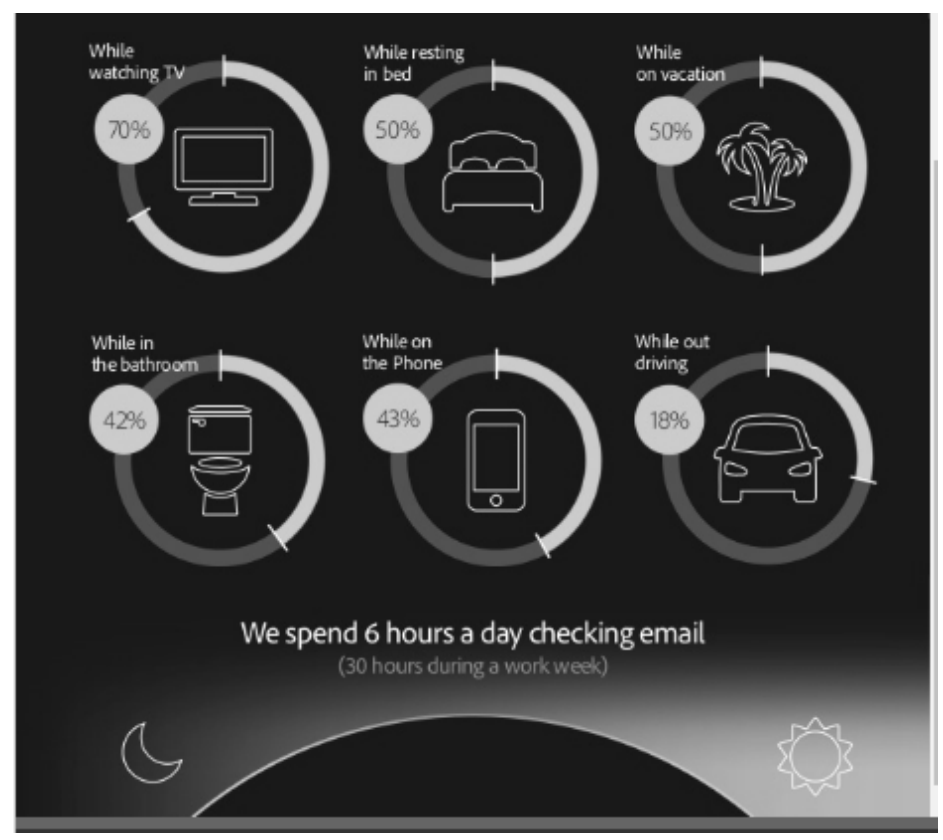

Figure no. 2. The time spent by users on checking email

Source: Naragon, K. (2015), Email, we just can't get enough, Adobe campaign study, https://blogs.adobe.com/conversations/2015/08/email.html

\section{Applying direct marketing techniques in the field of sport services and products}

The field of sports, whatever we can consider sport related products or sport related services or events that are implying a particular sport practice, is addressed in a particular manner by the marketing activity.

And if we further discuss about marketing communication applied in the field of sports, we can emphasize that communication principles are the same as we can encounter in the commercial products case but the execution of the communication process is different. The differences can rely on the 54 
fact that not every promotional effort in case of sports is made for a transactional sale. In many occasions we can talk about the effort to change attitudes, ideas and perceptions over self and surrounding reality, lifestyles etc. - the adoption of sport within the life of consumers or the persuasion related to a specific sport team, club or player etc.

Another peculiarity of the marketing communication effort within sport field is the one related to the need of integration of all communication mix instruments into an organic whole. This is needed because sport consumers are more than involved in long-lasting relationships with their teams, clubs, players etc. The emotions, trust and devotion related values are at the base of consumption acts within the sport activity. Consumers often are not seeing themselves as merely consumers but implied actors along their sport clubs or teams in their activity.

The same is happening with the individual sport consumption, the activity carried on regular basis needs full devotion and commitment from individuals, personal sport records are consumption motives along with the integration of sport into a system of beliefs and lifestyle.

To build up an effective sports loyalty scheme, organizations in the field are doing it through a certain stage related process on a long term as it can be seen in figure no. 3 .

Within this process direct marketing techniques will be used at a certain point, more precisely in the social bonding stage that is implying developing mutually beneficial relationships between the sport organization and customers.

In this stage the contact between organization and customer becomes more personalized and customer databases are used to send out personalized birthday cards or holidays cards. As the consumers will move to the third stage of loyalty, the need for personal contact between them and organization will increase. Along this process, direct marketing communication will offer the support for a personalized communication.

In sports field, direct marketing will imply as in other fields the effort to integrate different marketing functions and activities such as market research, segmentation, targeting, positioning, etc. with the use of direct 
Issue 4/2015

response media channels such as direct mail, telemarketing, interactive TV, email, etc.

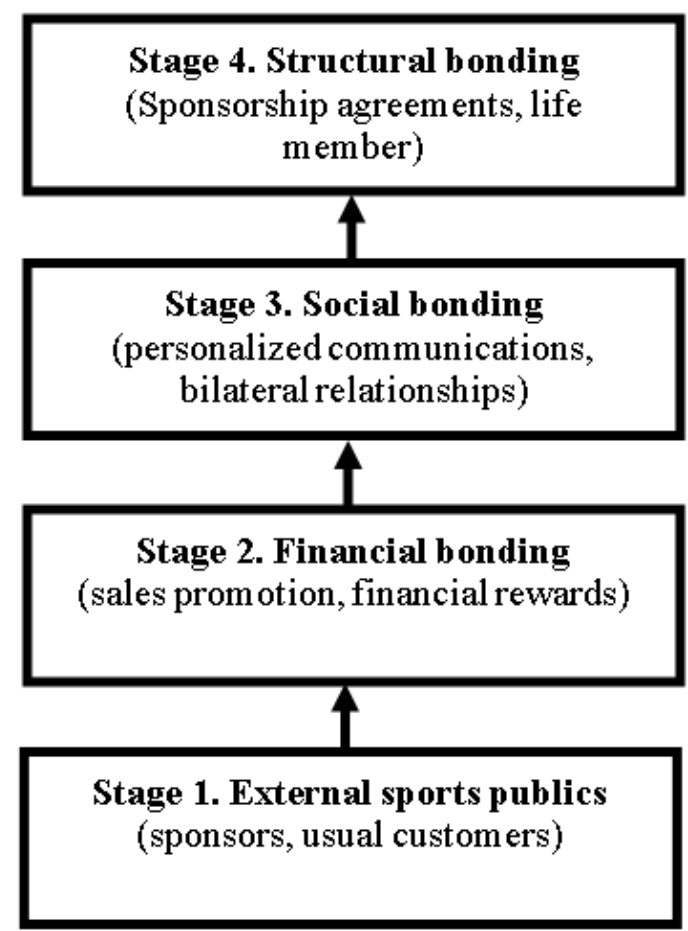

Figure no. 3. Sports loyalty scheme

Source: Beech, J., \& Chadwick, S., eds (2007), The marketing of Sport, Harlow: Pearson Education Limited, p. 228

Because of the fact that sport consumers are very loyal and less oriented to brands switching than other categories of consumers in other product or services related context, direct marketing is suitable to support communication and consumption altogether. In order to achieve that, every sport organization can benefit of the advantages offered by a well-structured customers' database. Through a continuous management of their databases, sport organizations can achieve a superior capacity to assess the opportunities and risks from the market. 

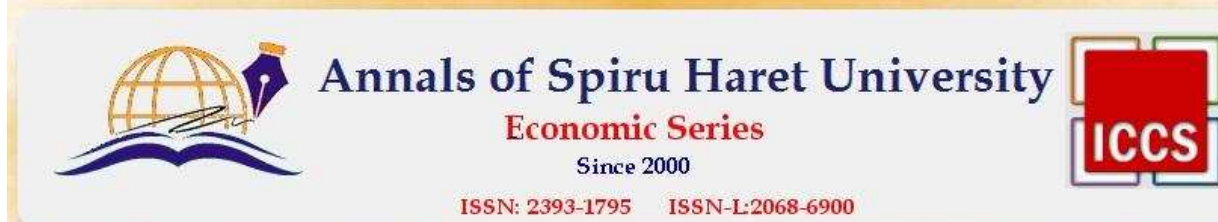

Issue 4/2015

Direct marketing techniques can also be used in order to minimize the financial risks that can affect an organization. In nowadays business environment and especially when we talk about a sport club, team or other organization implied in sports activity, the effort to continuously monitor and manage different types of risks is essential. The process to manage efficiently risks implies their categorization and proper evaluation. [Militaru \& Chenic, 2012]

The segments of customers that are riskier can be better managed with the help of a well-structured database. With the help of databases, sport organizations can develop four major types of marketing strategies in order to maximize their response regarding the customers' needs: customer retention strategy, customer reactivation strategy, product and service development strategy, promotion related strategy - implying cross selling between an existing customer base and a new one.

The multiple advantages offered by the email based communication with the customers' database are more visible in the field of sport consumers. Sport organizations can use this channel of communication to rapidly create customer registration within the database, to send personalized messages to different niche segments of customers, to obtain valuable marketing information from customers in real time, to offer up-todate information about a live sport event etc.

Also, the internet by itself creates a true revolution in the way that sport marketing is done. With the help of internet, sport organizations can improve ticketing for sport events, membership programs, sales dedicated for merchandise, live broadcasting of events, players' biographies distribution, and even improve the players training through live video streaming explanations and to transform their webpages into real virtual selling space and sponsor communication channel.

\section{Conclusions and future research}

On a brief, the multiple advantages that direct marketing techniques are bringing at the level of sport organizations can be summarized as follows: 


\section{Issue 4/2015}

- possibility to reach very easy a great number of potential and actual customers simultaneously;

- possibility to address with coherent and substantial messages to the sponsors and partners;

- the automation of the members' registration process, ticketing and selling merchandise;

- personalized messages and support for the personal relationship between sport organization employees and customers;

- enhancement of the consumption experience of sport live events;

- better management of sports communities; customers.

- opportunity to leverage influence on opinion leaders among sport

Taking account of the last trends related with direct marketing future developments, we can assume that sport products or services consumption will be more and more shaped by direct marketing influence.

Future research in the field can focus on how it can be optimized the creation and development of sport customer databases in order to offer all the information categories needed for sport organizations. As internet and mobile communication related instruments are becoming more and more advanced, development of direct marketing techniques will imply the use of these new features to a full extent in order to offer a more personalized communication experience for customers.

\section{References}

1. Beech, J. \& Chadwick, S., eds, The marketing of Sport (Harlow: Pearson Education Ltd., 2007).

2. Blakey, P., Sport Marketing (Exeter: Learning Matters Ltd., 2011).

3. Dischler, J., Building for the next moment (2015, http://adwords.blogspot.com/ 2015/05/building-for-next-moment.html).

4. Ferrand, A. \& McCarthy, S., Marketing the Sports Organization - building networks and relationships (London: Routledge Taylor \& Francis Group, 2009).

5. Funk, D.C., Consumer behaviour in Sport and Events: Marketing action (Oxford: Elsevier-Butterworth-Heinemann, 2008). 
6. Irwin, R.L., Sutton, W.A. \& McCarthy, L.M., Sport Promotion and Sales Management, Includes tools and insights from top industry professionals (Champaign: Human Kinetics, 2008).

7. Lella, A., Lipsman, A. \& Martin, B., The 2015 US Mobile App Report (comScore Media Metrix Multi-Platform \& Mobile Metrix, https://www.comscore.com/Insights/Presentations-and-Whitepapers/2015/The2015-US-Mobile-App-Report, 2015).

8. Lella, A. \& Lipsman, A., The U.S. Mobile App Report (http://www.comscore.com/Insights/Presentations-and-Whitepapers/2014/The-USMobile-App-Report, 2014).

9. Militaru, M. \& Chenic, A.Ş., "Risk management and the implications to business success", Revista economică (Supplement, no. 2, 2012), p. 233-238.

10. Morrison, K., Social Ad Spending Predicted to Grow to $\$ 24.2$ Billion by 2016 (Infographic) (http://www.adweek.com/socialtimes/social-ad-spending-predictedto-grow-to-24-2-billion-by-2016-infographic/627631, 2015).

11. Mullin, J.B., Hardy, S. \& Sutton, A.W., Sport marketing, fourth edition (Champaign: Human Kinetics, 2014).

12. Naragon, K., Email, we just can't get enough, Adobe campaign study (https://blogs.adobe.com/conversations/2015/08/email.html, 2015).

13. Pickton, D. \& Broderick, A., Integrated Marketing Communications, $2^{\text {nd }}$ edition (Harlow: Pearson Education Ltd., 2005).

14. Tapp, A., Principles of Direct and Database Marketing (Harlow: Pearson Education Ltd., 2005).

15. http://www.hubspot.com/marketing-statistics. 
